\title{
Importance of learning Global Health in strengthening Primary Health Care: an experience
} from Nepal

Randhir Sagar Yadav ${ }^{1 *}$, Shumneva Shrestha ${ }^{1}$

${ }^{1}$ Tokha Chandeshwori Primary Health Center, District Public Health Office, Kathmandu, Nepal

\section{Received:}

21 July 2018

Revised:

11 December 2018

Accepted:

26 January 2019

*Corresponding author

sagar.randhir@gmail.com https://orcid.org/0000-

0003-4075-3544

\section{Abstract}

Global health is a multidisciplinary and interdisciplinary approach of dealing transnational determinants of health. Strengthening health care institutions is vital for achieving universal health care. It also favors global health outcomes as it bridges gaps of health inequalities and saves numerous lives. In Nepal, the Institute of Medicine, Tribhuvan University is offering global health course since 2013. This paper discusses practical application of the learnings from the global health course to make commendable achievements at a primary health center. The global health course can be the foundation for transforming clinicians and public health practitioners into promising global health leaders. This will contribute to improve basic health care services, quality care, and vaccination program to improve the health of population. Therefore, global health course should be an imperative of medical education to capacitate doctors working in these settings to better understand the social determinants of disease prevention, care and rehabilitation.

Keywords: Global health; global health course; medical education; strengthening health institution

Tweetable abstract: Global health should be integrated in medical education to inspire young doctors to strengthen health institution and work for health equity.

\section{Introduction}

Koplan and colleagues (2009) proposed a working definition of global health as "an area or study, research, practice that places a priority on improving health and achieving equity in health in all people worldwide" [1]. Similarly, Macfarlane et al. (2008) have described global health as "worldwide improvement of health, reduction of disparities, and protection against global threats that disregard national borders" [2]. Global health is recommended to be incorporated in the medical curricula to inspire medial graduates to work in underserved part and guide professionals to appreciate health issues in global context $[3,4]$. Public health institutions have a vital role in enhancing health care system that ultimately promotes global health outcomes. To achieve it, these institutions should safeguard efficiency, effectiveness, equity and sustainability [5]. Strengthening public health institutions can save more lives for reasonably lesser expenses [6].

Institute of Medicine (IOM), Tribhuvan University, Nepal has been offering global health course (GHC) regularly in collaboration with Duodecim and University of Tampere, Finland since 2013 to educate medical, dental, nursing, public health and veterinary students [7,8]. Global health learning and practice is of utmost importance in strengthening the health institutions. In this regard, a course on global health can be a stepping stone to attain desired implications of global health in Nepalese context.

\section{Community Medicine and Public Health in Medical Curricula}

Community based teaching has been integrated in medical education since long in Nepalese medical colleges [9,10]. IOM, Tribhuvan University provides community based education both through theoretical and practical part particularly through community health diagnosis, concurrent field visit with the family of patients and district health system management [9]. These practical field studies help medical students get acquainted with structures of health systems and problem solving skills, socioeconomic determinants of health/ diseases and structural/functional management of health care system at the district level and below. Furthermore, students are also taught on epidemiological study, program planning and critical analysis of public health services. Apart from these, community medicine practical studies and didactics of public health contents are also part of the medical curriculum. Indeed, it helps encourage novice doctors to take public health responsibilities in their professional platform.

Pati et al. (2017) have suggested integration of global health education (GHE) with public health to create a comprehensive curriculum in India. Moreover, global health training in professionals help them deal medical concerns and health issues from global perspective. Thus, they have advocated for standardized global health curricula in medical education with the emerging interest and rising cognizance on the new paradigm of global health [4]. Even though medical students in Nepal have been taught community medicine and public health in an integrated way for years, introduction of global health is at a budding stage in the form of a training program. Moving ahead, it is a high time GHE is considered in the medical education. 


\section{Global Health in Medical Education}

Global health has been included in medical education in various developed nations for the past few decades. However, history of global health course in low and middle income countries including Nepal is not very long [4]. Globally, there is rising attraction towards global health practice among medical students. For example, GHE among US graduates was found as a crucial motivating factor for working for underserved population and/or pursue career in primary health care [11]. Similarly, the opportunity to serve disadvantaged people was found to be the motivating element for them to be involved in global health [12]. There may be other associated factors in motivating to serve disadvantaged people and involve in global health. It is irony that patients who cannot access health care and physicians unwilling to work for them is on rise. Any level of efforts to drive service providers to care for those underserved population are substantial [11]. In Nepal, majority of people do not enjoy decent health care because of problems related to accessibility, affordability, quality of care and availability of health services [13,14]. Health care utilization has a significant pro-rich distribution while poor people are not found to make more use of public health services in urban Nepal [15]. It is also often observed that many doctors hesitate to work in unprivileged parts of the country [16]. Similarly, in a cross sectional study in students in their last two years of medical education in Nepal, only 1 in 10 medical students had career intention of working in rural Nepal following graduation [17].

Contrarily, medical students studying under the Government's scholarship are bound to work for two years in remote Primary Health Centers (PHCs) and hospitals of Nepal following graduation and thus have become an important part of Nepalese primary health care system. In such scenario, GHE for those medical students may inspire them to work in rural areas and can be instrumental in alleviating health inequity and inaccessibility to some extent. The authors served at Tokha Chandeshwori PHC situated at outskirts of Kathmandu as per above mentioned provision and made a team effort to practically apply our understanding of community medicine, public health and global health to strengthen our PHC and enhance its services. The GHC conducted by IOM in 2013 and 2015 consisted of participants from different partner nations namely, Nepal, Finland, Chile, Tanzania and Philippines [7,8]. Since then the number of aspirants of the GHC kept rising such that Global Health Unit, IOM started yearly National GHC since 2015.

\section{Learning from Global Health Course}

The authors were the participants of the $1^{\text {st }}$ National GHC that was held from December 6-16, 2015. The understanding of broader arena of global health has aspired us to be a global health leader of future. We had rigorous theoretical classes on social determinants of health, health financing, global health as a discipline, globalization affecting health, infectious and non-infectious diseases, emerging and remerging diseases, adolescent, sexual, reproductive health and safe-motherhood, sustainable development goals, global health ethics and professionalism, human resources for health, health indicators and so on. These topics of global health importance had immense role in motivating us to work for health equity and provide services with optimum utilization of skills and available human and physical resources. Visits to district hospital and PHC helped us appreciate the relevance of global health implications in those settings. It was indubitably the inciting moment to make the purpose of visit applicative at our workplace. Patients and public have high expectations of attaining quality health care from physicians. Despite the resource constraints, patients cannot be barred of quality care. This feeling kept us accountable to justify our learnings of GHC at our workstation which facilitated to produce commendable improvements in health indicators, service enhancement and extension, community participation, etc. through capable workforce and health institution strengthening to ensure best possible results. We realize that GHE is required for medical students to learn health issues from global perspective and capacitate physicians to work in the best interest of patient care, public health system and global health outcomes.

\section{Application of learning from Global Health Course at workplace}

GHC gave an impetus to our understanding about application of global health in primary health care settings. Studying community medicine and doing field practicum in medical college gave us information on community and district level health systems. We were well aware of our future role in such system. Having acknowledged the health systems and its elements from institutional and public viewpoint, GHC aided to knowing health issues through global health perspectives. It helped us to be determined in working for health equity and social justice. PHC strengthening and quality service delivery became the ultimate goal. GHC helped us understand about different health programs as well as health indictors and its implication in health system. Implementation of all the public health programs were equally valued as caring individual patients. Existing services were strengthened through program specific strategies, monitoring and evaluation. GHC imparted to us the knowledge on need and importance of contributing to global health from individual, team and institutional level. It also motivated us to put all possible individual and team efforts to enhance services, increase service utilization and improve overall health status of the community as well as minimize the prevailing heath inequities. Therefore, we were able to practically apply our learning from GHC to bring about various positive changes at our workplace. In the fiscal year 2016/17, there were significant improvements in major health indicators namely OPD services, laboratory services, antenatal care, nutrition program, immunization coverage, contraceptive prevalence rate and female community health volunteers (FCHVs) program in comparison to the earlier two fiscal years (figure 1) $[18,19]$. Similarly, there was an improvement in reporting of community based integrated management of neonatal and childhood illnesses (CB-IMNCI) like acute respiratory tract infections and diarrheal diseases by the FCHVs. There were improvements in number of registered Tuberculosis cases, sputum conversion rate, cure rate and treatment success rate [18]. Beside these free national public health programs, addition of free services like tele-dermatology, cervical cancer screening, oral cancer screening, self-breast examination education and audiovisual health education programs were further efforts. Our PHC was the only health institution of Kathmandu valley which provided free anti-rabies vaccination to public beside Sukraraj Tropical Hospital, Teku, one of the central level hospital 
in Nepal. It was started from April 2017 after tireless determination. Laboratory strengthening and equipping with analyzer and thus performing a large number of investigations in addition to starting X-Ray and ECG services along with managing free medicines round the year were other major accomplishments [19]. Availability of free medicines and provision of laboratory, X-Ray and ECG services at a very nominal operating cost with a provision of free services for needy or unaffordable patients favored service seeking behavior of the community. Mothers' group interest in woman's health was appreciable. Addition of long acting contraceptive services (implants and intrauterine device) in addition to previously available barrier and injectable forms enhanced family planning services. Provision of antenatal investigation package (all blood and urine tests) for just NRs. 300 complemented antenatal program. First week of every month was observed as growth monitoring week and full immunization was declared within proposed timeframe with appreciable community participation. Program specific activities as well some integrated activities were carried out to help people get available free services in their own community and need not travel and spend money to seek similar services at a different center. There was increase in average visits of patients/clients for health care services. Elderly, women, children and marginalized ones were major service seeking groups. We believe these efforts helped increase service utilization, minimize health inequities to some extent and improve overall health in that community.

\section{Global Health in Medical Curricula}

Despite a long history of integrating GHE in US and Canadian medical schools, there is lack of uniformity in the curricula [3]. Similarly, GHE is delivered in a fragmented way in India even though it is yet to get enough focus [4]. The growing interest of medical students in global health creates an opportunity for the global health tutors and medical colleges to connect their students to global health objectives and principles which would ultimately be helpful in patient care and population at a broader level. Depending on the resources and interest, high-intensity model where motivated candidates seek the GHE or low-intensity model where a baseline GHE is given to all students or combination of both can be an option for the medical colleges [3]. Participants of GHC at IOM are selected among interested applicants. Yet many motivated candidates sadly cannot get through. Inadequate resources and financial constraints are the biggest limitations. Leadership in institutionalizing GHE is of paramount importance. University-wide participation, endorsement of dean and involvement of counterpart institutions' leadership are recommended for the success of GHE [3]. It is high time that GHC gets incorporated in the medical curriculum at universities such that all the students understand the basics about global health through uniform curricula. This will help to produce physicians who can bring health equity, strengthen our health system and ultimately contribute to global health perspective.

\section{Conclusion}

GHC should be regarded as an imperative of medical education. It should be integrated in the medical curricula at universities such that all the medical students acquire basic understanding of global health. They can apply it at their professional arena following graduation. Imparting knowledge to deal health issues through global perspective will strengthen health institutions, enhance health system and ultimately favor global health outcomes.

\section{Acknowledgements}

We are very thankful to Mr. Pratik Khanal, member of Academic sub-committee of Global Health Unit, Institute of Medicine and Mr. Prem Basel, Department of Community Medicine and Public Health as well as member of Global Health Unit, Institute of Medicine for reviewing and editing this manuscript.

\section{Conflict of Interests}

None declared 


\section{References}

1. Koplan JP, Bond TC, Merson MH, Reddy KS, Rodriguez MH, Sewankambo NK, Wasserheit JN; for the Consortium of Universities for Global Health Executive Board. Towards a common definition of global health. The Lancet. 2009;373(9679):1993-95. (https://doi. org/10.1016/S0140-6736(09)60332-9 )

2. Macfarlane SB, Jacobs M, Kaaya EE. In the name of global health: trends in academic institutions. J Public Health Policy. 2008;29:383-401. (https://www.ncbi.nlm.nih.gov/pubmed/19079297)

3. Khan OA, Guerrant R, Sanders J, Carpenter C, Spottswood M, Jones DS et al. Global health education in U.S. Medical schools. BMC Medical Education 2013;13:3. (https://doi.org/10.1186/1472-6920-13-3 )

4. Pati S, Sinha R, Panda M, Pati S, Sharma A, Zodpey S. Global Health Teaching in India: A Curricular Landscape. Front Public Health. 2017;5:259. (https://www.ncbi.nlm.nih.gov/pmc/articles/PMC5623664/ )

5. Bloland P, Simone P, Burkholder B, Slutsker L, De Cock KM. The Role of Public Health Institutions in Global Health System Strengthening Efforts: The US CDC's Perspective. PLoS Med. 2012;9(4):e1001199. (https://doi.org/10.1371/journal.pmed.1001199 ) 6. Frieden TR, Koplan JP. Stronger national public health institutes for global health. The Lancet. 2010;376:1721-22. (https://doi. org/10.1016/S0140-6736(10)62007-7)

7. Amatya A, Basel P. Why study global health? Kathmandu Univ Med J. 2014;12:87-8. (https://www.nepjol.info/index.php/KUMJ/ article/view/13650 )

8. Global Health Unit, National Center for Health Professions Education (NCHPE), IOM, Kathmandu, Nepal. Available at http://www. ghciom.com

9. Marahatta SB, Sinha NP, Dixit H, Shrestha IB, Pokharel PK. Comparative study of community medicine practice in MBBS curriculum of health institutions of Nepal. Kathmandu Univ Med J (KUMJ). 2009;7(28):461-469. (http://www.kumj.com.np/ issue/28/461-469.pdf )

10. Marahatta SB. Community based medical education: prospects and challenges. Kathmandu Univ Med J (KUMJ). 2009;7(27):194195. (http://www.kumj.com.np/issue/27/4-5.pdf)

11. Bazemore AW, Goldenhar LM, Lindsell CJ, Diller PM, Huntington MK. An International Health Track Is Associated With Care for Underserved US Populations in Subsequent Clinical Practice. J Grad Med Educ. 2011;3(2):130-7. (https://www.ncbi.nlm.nih.gov/pmc/ articles/PMC3184923/)

12. Withers M, Browner CH, Aghaloo T. Promoting volunteerism in global health: lessons from a medical mission in northern Mexico. J Community Health. 2013;38(2):374-84. (https://link.springer.com/article/10.1007/s10900-012-9627-z )

13. Beine D. Saano Dumre Revisited: Changing Models of Illness in a Village of Central Nepal. 2001.

14. Rasali DP (2007, October 7). Challenges in Nepal's new era: health inequalities, inequalities and disparities. Canada Foundation for Nepal. Available at http://cffn.ca/2007/10/challenges-in-nepals-new-era-health-inequalities-inequalities-and-disparities/

15. Saito E, Gilmour S, Yoneoka D, et al. Inequality and inequity in healthcare utilization in urban Nepal: a cross-sectional observational study. Health Policy Plan. 2016 Sep;31(7):817-824. (https://www.ncbi.nlm.nih.gov/pmc/articles/PMC4977425/ )

16. Gautam, M. (2017, February 21). Govt struggling to hire specialist doctors. The Kathmandu Post. Available at http:// kathmandupost.ekantipur.com/printedition/news/2017-02-21/govt-struggling-to-hire-specialist-doctors.html.

17. Huntington I, Shrestha S, Reich NG, et al. Career intentions of medical students in the setting of Nepal's rapidly expanding private medical education system. Health Policy Plan 2012;27:417-28. (https://www.ncbi.nlm.nih.gov/pubmed/21880690 )

18. District Public Health Office. Annual Report 2073/74, District Public Health Office, Department of health Services, Ministry of Health and Population, Kathmandu. 2017.

19. Shrestha, S. (2017, August 1). The changing Tokha Chandeshwori Primary Health Center (in Nepali). News of Tokha. Retrieved from http://newsoftokha.com 